\title{
VARIAÇÃO E PRECONCEITO LINGUÍSTICO NA LÍNGUA PORTUGUESA ENTRE FALANTES COM BAIXA ESCOLARIDADE
}

\author{
VARIATION AND LINGUISTIC PREJUDICE IN THE PORTUGUESE LANGUAGE \\ AMONG SPEAKER SPEAKERS
}

\author{
Mara Cristina Pereira ${ }^{\mathrm{I}}$ \\ Fatima Christina Calicchio ${ }^{2}$
}

\begin{abstract}
RESUMO: O presente artigo tem como objetivos analisar e apresentar resultados obtidos através de um trabalho de entrevistas e análise qualitativa da variação linguística apresentada entre falantes da língua portuguesa com baixa escolaridade. Também se procurou identificar o preconceito linguístico que os falantes entrevistados sofrem em seus cotidianos decorrentes da variação linguística utilizada por eles e de que maneira isso os afetam. Parte majoritária dos dados foi coletada entre participantes adultos que frequentam um grupo no Centro de Referência em Assistência Social no município de Rondonópolis. As pesquisas realizadas neste trabalho se deram através de estudos bibliográficos teóricos e de levantamentos de dados em campo.
\end{abstract}

Palavras-chave: Escolaridade. Falantes. Discriminação. Diversidade linguística.

ABSTRACT: This article aims to analyze and present results obtained through interviews and qualitative analysis of linguistic variation among Portuguese speakers with low education. We also sought to identify the linguistic prejudice that the interviewed speakers suffer in their daily lives due to the linguistic variation they use and how it affects them. Most of the data were collected from adult participants attending a group at the Referral Center for Social Assistance in the municipality of Rondonópolis. The research carried out in this work took place through theoretical bibliographic studies and field data surveys.

Keywords: Schooling. Speakers. Discrimination. Linguistic Diversity.

\section{INTRODUÇÃO}

Nosso país é tido como um dos mais diversos culturalmente do mundo. Isso ocorre em vários aspectos socioculturais, e a língua, sendo um fator tão importante entre uma nação, não poderia ficar alheia a toda essa diversidade. As variações linguísticas, por refletirem e representarem a identidade de seus povos são objetos constantes de pesquisas, artigos, monografias, etc. junto às comunidades que estudam a escrita e, sobretudo, a fala.

\footnotetext{
1 Acadêmica do Curso de Licenciatura Português- Inglês Letras , Centro Universitário de Maringá UNICESUMAR. Bolsista PIC/CNPq-UniCesumar.E-mail: mara.marianor4@gmail.com.

${ }^{2}$ Orientadora, Mestra em Letras na área de Estudos Linguísticos pela Universidade Estadual de Maringá (2014). Graduada em Letras pela Universidade Estadual de Maringá (2009). Docente do Centro Universitário de Maringá. E-mail: fatima.calicchio@unicesumar.edu.br.
} 
O aprofundamento nesse assunto causa sempre muito interesse, uma vez que há um universo riquíssimo de variações que vão desde as mudanças lexicais por regiões até certas particularidades nas pronúncias de alguns vilarejos, afinal, a língua é um sistema heterogêneo, dotado de autonomia e diversidade, porém essa dinamicidade encontrada na língua escrita e, principalmente, na modalidade falada, muitas vezes, é classificada como erro e acarreta preconceito linguístico para os falantes menos escolarizados.

A partir desses pressupostos, este artigo tem como objetivo geral a busca pelo entendimento de como as variações linguísticas dos falantes de língua portuguesa com baixa escolaridade acabam por incorrerem em preconceito linguístico por uma parte considerável de nossa sociedade.

\section{FUNDAMENTAÇÃO TEÓRICA}

A língua falada, diferentemente da língua escrita, não é algo estanque, ou seja, o falar de uma determinada comunidade está sempre em um processo contínuo de variação e mudança, o qual é um acontecimento genuíno e inerente em todas as culturas humanas existentes. Entretanto, parte de nossa sociedade, principalmente a camada mais privilegiada economicamente, insiste em classificar a diversidade linguística como algo fora dos padrões considerados "certos", são as chamadas normas que se encontram prescritas em gramáticas tradicionais. A esse fenômeno recorrente, descrito como preconceito linguístico, o pesquisador e Sociolinguista Marcos Bagno, autoridade reconhecida no assunto, escreveu o livro Preconceito linguístico - o que é, como se faz, no qual, majoritariamente, este artigo será embasado. Segundo o autor: "Uma receita de bolo não é um bolo, o molde de um vestido não é um vestido, um mapamúndi não é o mundo... Também a gramática não é a língua.” (BAGNO, 1999, p. 9).

Desta forma, fica clara a intencionalidade do autor no tocante à visão que não se pode ter a língua falada como algo engessado, uma vez que a norma escrita é um referente dessa língua e não o produto final, sendo a oralidade suscetível às variações linguísticas e não condicionadas às normas prescritas em gramáticas tradicionais.

\section{I UMA BREVE CONTEXTUALIZAÇÃO DA VARIAÇÃO LINGUISTICA}

O século XX trouxe uma grande diversidade nos avanços do estudo da língua, sobretudo no aspecto da língua falada. Entre as tantas correntes linguísticas surgidas neste século, destacase a Sociolinguística, que surgiu com objetivo de estudar as manifestações contidas na oralidade. A partir da década de 6o, o linguista William Labov ([1968] 2006) desenvolveu importantes 
estudos com foco nas variações linguísticas:

A Teoria da Variação e Mudança Linguística (também chamada Sociolinguística Quantitativa ou Laboviana) tem como objeto de estudo a variação e mudança da língua no contexto social da comunidade de fala. A língua é vista pelos sociolinguistas como dotada de "heterogeneidade sistemática", fator importante na identificação de grupos e na demarcação de diferenças sociais na comunidade. O domínio de estruturas heterogêneas é parte da competência linguística dos indivíduos. Nesse sentido, a ausência de heterogeneidade estruturada na língua seria tida como disfuncional (cf. WEINREICH; LABOV; HERZOG [1968] 2006, p.IoI).

Desta forma, podemos constatar que Labov, Weireinch e Herzog veem com outra perspectiva sobre a língua, contrariando, assim, a teoria de vertente estruturalista saussuriana, na qual a língua era analisada somente sobre aspectos internos, desconsiderando os aspectos pragmáticos e socioculturais existentes na língua falada, os quais são tão importantes quanto às concepções estruturalistas.

Assim, a sociolinguística veio para estudar e explicar a língua de uma forma centrada na diversidade linguística além da escrita, sobretudo com foco na oralidade em suas variadas manifestações, englobando seus fatores internos estruturais sim, mas também, fatores externos regionais, lexicais, sociais, históricos, entre outros.

Bagno (1999) explica como historicamente foi construída uma imagem supervalorizada da norma escrita considerada culta e como isso contribuiu para o conceito de "certo" e "errado" na oralidade:

O que aconteceu, ao longo do tempo, foi uma inversão da realidade histórica. As gramáticas foram escritas precisamente para descrever e fixar como "regras" e "padrões" as manifestações linguísticas usadas espontaneamente pelos escritores considerados dignos de admiração, modelos a ser imitados. Ou seja, a gramática normativa é decorrência da língua, é subordinada a ela, dependente dela. (BAGNO,1999, p. 59).

Analisando por esse viés, evidencia-se ainda mais o fato de que a língua falada é um fator primordial a ser considerado nos estudos linguísticos. O falante está inserido em sociedade, a qual se transforma e encontra-se em constante mudança, sendo a língua, escrita ou falada, um componente muito importante desse universo, não estando alheia a esse processo de transformações.

\subsection{O PRECONCEITO LINGUISTICO ENTRANHADO NA CULTURA BRASILEIRA}

Nossa sociedade, constituída de culturas diversas, resultantes de um país colonizado, o qual passou por processos de imigrações e aculturação dos povos indígenas que já habitavam em 
nossas terras, tem uma gama de sotaques, gírias, linguajares regionais, com léxicos muitas vezes conhecidos apenas pelos integrantes de determinadas comunidades, dentre outras variações linguísticas.

Essas diferenças na língua falada não são vistas como uma riqueza cultural, muito pelo contrário, convencionou-se que todo falar distinto da norma tida como culta, a que se encontra prescrita na Gramática Normativa, é considerado "errado", “exótico”, "pitoresco" ou "engraçado". Para um melhor entendimento, façamos uma breve diferenciação entre discriminação e preconceito embasado na explicação de Ricardo Antonio Andreucci:

A "discriminação", por sua vez, expressa a quebra do princípio da igualdade, como distinção, exclusão, restrição ou preferência, motivado por raça, cor, sexo, idade, trabalho, credo religioso ou convicções políticas.

Já o “preconceito” indica opinião ou sentimento, favorável ou desfavorável, concebido sem exame crítico, ou ainda atitude, sentimento ou parecer insensato, assumido em consequência da generalização apressada de uma experiência pessoal ou imposta pelo meio, conduzindo geralmente à intolerância. (ANDREUCI, 2016, p.I)

Podemos perceber, assim, que o preconceito está mais ligado à subjetividade, enquanto a discriminação encontra-se mais no campo perceptível, ou seja, essa última é mais fácil de ser identificada e combatida. O preconceito linguístico ainda não chegou explicitamente ao nível da discriminação, porém já acarreta um caminho semelhante a outros preconceitos que resultaram em discriminações facilmente identificáveis. Por ser mais sútil, diferentemente de outros preconceitos, tais como o racial, por gênero, social, por exemplos, o preconceito linguístico é bem difícil de combater, ou até mesmo de se identificar. Isso se dá porque ele é praticado por boa parte da população, a qual acredita piamente que exista uma forma "correta" de falar. Boa parte dessa visão equivocada foi construída e alimentada pela comunidade letrada, conforme afirma Bagno (1999):

"O preconceito linguístico está ligado, em boa medida à confusão que foi criada, no curso de história, entre língua e gramática normativa. Nossa tarefa mais urgente é desfazer essa confusão”. (BAGNO,1999, p. 9).

Analisando esse conceito do autor, podemos entender que o preconceito linguístico tem suas raízes na Gramática Normativa, a qual tem sim sua importância, mas não pode ser reconhecida como a única detentora da língua portuguesa, desconsiderando seus falantes com suas variações linguísticas. Também é importante destacar a necessidade de que esse mal entendido, produto existente em decorrência da discrepância entre língua e fala, seja desfeito, uma vez que, apesar de certo combate e conscientização do quão maléfico esse preconceito 
linguístico é para os falantes, ainda há maneiras, mesmos que sem intencionalidade por parte de quem faça tais correções linguísticas, que acabam por naturalizá-las. Para evidenciarmos essa afirmação, vejamos este argumento de Bagno:

O preconceito lingüístico fica bastante claro numa série de afirmações que já fazem parte da imagem (negativa) que o brasileiro tem de si mesmo e da língua falada por aqui. Outras afirmações são até bem-intencionadas, mas mesmo assim compõem uma espécie de "preconceito positivo", que também se afasta da realidade. (BAGNO,1999,p.r3,grifo do autor).

Outro fator que contribui muito na disseminação do preconceito linguístico é o da mídia brasileira, pois ela influencia parte do público que a acompanha através dos vários meios de comunicações existentes, seja pelo gênero jornalístico, ou até mesmo no campo do entretenimento, conforme enfatiza Bagno:

É um verdadeiro acinte aos direitos humanos, por exemplo, o modo como a fala nordestina é retratada [pg. 43] nas novelas de televisão, principalmente da Rede Globo. Todo personagem de origem nordestina é, sem exceção, um tipo grotesco, rústico, atrasado, criado para provocar o riso, o escárnio e o deboche dos demais personagens e do espectador. (BAGNO, 1999, p.13, grifo do autor).

Mediante essa exposição do autor, podemos constatar como a mídia estigmatiza determinado falares ainda mais que outros. O preconceito linguístico é uma realidade, dessa forma, faz-se necessário seu combate e a desconstrução de conceitos embasados em normas e padrões. Para isso, necessita-se de que a sociedade em geral atente-se para o fato de que a língua é heterogênea e sujeita as variações linguísticas de milhões de falantes em nosso país.

\section{METODOLOGIA}

Este artigo, de cunho exploratório, foi desenvolvido a partir de duas etapas, sendo a primeira pesquisa bibliográfica e a segunda pesquisa de campo qualitativa. A etapa bibliográfica embasou-se por meio dos referenciais teóricos de linguistas, filólogos, pesquisadores e professores que atuam na área da Sociolinguística.

Já a pesquisa de campo se deu no município de Rondonópolis- MT, incialmente, com a intenção de apresentação em um grupo de 30 (trinta) adultos entre 30 e 70 anos com baixa escolaridade, dos quais seriam io (dez) participantes convidados a responderem o questionário dessa pesquisa. Entretanto, no desenvolver da pesquisa, verificou-se ser melhor convidar individualmente cada frequentador do referido grupo, dos quais 4 ( quatro) mulheres e mais uma não participante do grupo, entre 50 e 69 anos, aceitaram participar voluntariamente da pesquisa. A escolaridade das entrevistadas é da $3^{\circ}$ até $7^{\circ}$ série, ou seja, todas com ensino 
fundamental incompleto.

O local escolhido para realização dos encontros previstos para aplicação do questionário se deu pelas próprias entrevistadas. As entrevistas foram realizadas nos meses de julho e agosto deste ano. No momento da entrevista, foi explicado às contempladas que se tratava de uma pesquisa sobre o falar da língua portuguesa, sem, contudo, mencionar o preconceito linguístico, com intuito de não influenciarmos nas respostas das entrevistadas.

$\mathrm{Na}$ coleta dos dados procuramos evidenciar a variação da língua portuguesa brasileira e também constatarmos quais os principais preconceitos que sofreram ou sofrem os falantes da língua portuguesa com baixa escolaridade. Utilizamos um questionário contendo 5 ( cinco) perguntas semiestruturadas, com entrevistas gravadas e posteriormente transcritas na íntegra para análise fidedigna do conteúdo.

O questionário utilizado nas entrevistas abordaram as seguintes questões:

I. Você acha que fala diferente em relação a outras pessoas?

a. Qual ou quais palavras você mais nota diferença entre os falantes com quem convive?

b. Alguma vez você falou alguma palavra "errada" e alguém lhe corrigiu? Se sim, como foi?

2. Como você se sentiu diante dessa correção/ Qual a sensação que você tem/ teve?

3. Você acha que exista uma maneira "certa" de falar?

\section{DISCUSSÃO E RESULTADOS}

Neste tópico, apresentaremos a análise dos dados obtidos através das respostas das entrevistadas. As questões serão divididas e apresentadas conforme as perguntas foram aplicadas. Após leitura minuciosa do conteúdo coletado nas entrevistas, identificamos e separamos as categorias existentes nos discursos das participantes e, assim, dividiremos, para um melhor entendimento, em eixos explicativos e comparativos, atentando-se sempre para o arcabouço teórico que embasa essa pesquisa.

Utilizaremos pseudônimos em lugar dos nomes reais das participantes para preservarem seus anonimatos, contudo, a idade e a escolaridade serão divulgadas por não comprometerem a integridade das entrevistadas. Através da pergunta inicial, procuramos indícios de consciência por parte das entrevistadas referente à percepção de seus falares em comparação aos falantes com quem convivem, o resultado observado foi este: 
Gráfico r: Consciência do falar diferenciado ou não na concepção das entrevistadas.

\title{
1- Você acha que fala diferente em relação a outras pessoas?
}

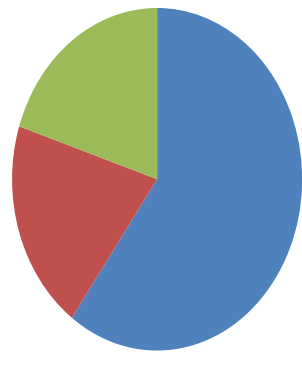

\author{
$60 \%$ acreditam falar \\ diferente \\ $20 \%$ acreditam não falar \\ diferente \\ $20 \%$ não tem certeza se \\ falam diferente
}

Fonte: autora

Os resultados obtidos neste tópico mostram que a maioria das entrevistas (6o\%) acreditam falar diferente de outros falantes com quem convivem, porém nos chama atenção o fato de que parte das entrevistadas, mesmo sem saber empiricamente o que é a variação linguística, tem sim consciência que ela exista e que todos os agentes constituintes envolvidas na fala utilizam-se dela, conforme podemos constatar nas respostas das seguintes entrevistadas:

\footnotetext{
“Ah, eu não sei ,né, pode que outras pessoas acham que eu falo diferente, mas, eu falar diferente? Não sei ,eu acho que... não sei, não sei responder, porque eu acho que muitas pessoas podem achar que eu falo diferente, né? Se eu falo diferente, isso não sei responder pra você. “( Azaleia ,5o anos, $4^{\circ}$ série fundamental I) .

“É, eu não acho não, né? Porque as pessoas, cada um fala de um jeito, né? Acho que não falo tão diferente dos outros não, né? Um pouco errado, um pouco certo.” ( Margarida,68 anos, $4^{\mathrm{O}}$ série fundamental I).
}

Com base nessas falas das entrevistadas, fica evidente a concepção da diversidade existente na oralidade e seus traços linguísticos variados, ainda que inconscientemente, eles são utilizados pelos falantes de uma mesma comunidade de fala, e isso é um fenômeno comum dentre uma mesma sociedade, conforme afirma Labov : "uma comunidade de fala não pode ser concebida como um grupo de falantes que usam todos as mesmas formas; ela é mais bem definida como um grupo que compartilha as mesmas normas a respeito da língua" (2008 [1972], p. I88).

Já os resultados sobre a segunda questão: Qual ou quais palavras você mais nota diferença entre os falantes com quem convive? 60\% das participantes entrevistadas relataram perceber falar 
diferente dos demais falantes com quem convivem, relatando, inclusive, exemplos de quais palavras observaram, enquanto que $40 \%$ não souberam exemplificar. Vejamos os seguintes trechos das entrevistas em que é possível observamos os vocábulos, destacados pela autora, explicitados pelas entrevistadas que souberam identificá-los:

"Pizza, a palavra pizza, ( que soa como pritissa com ela pronunciando), eu acho que não falo direito [...].” (Magnólia,63 anos, $3^{\circ}$ série fundamental I).

"Sair, pra sair, né? Eu falo ‘saî', não é 'saî', eles falam direito e eu falo 'saî', não sei [...]." (Violeta,66 anos, $3^{\circ}$ série fundamental I).

“ Tá, os guris ( filhos) tiram muito sarro de mim porque eu falo 'poblemas', diferente, né?" ( Azaleia ,5o anos, $4^{\mathrm{o}}$ série fundamental I).

Vejamos mais claramente os dados analisados no gráfico 2 :

Gráfico 2: Identificação ou não de variações linguísticas nos vocábulos falados pelas entrevistadas.

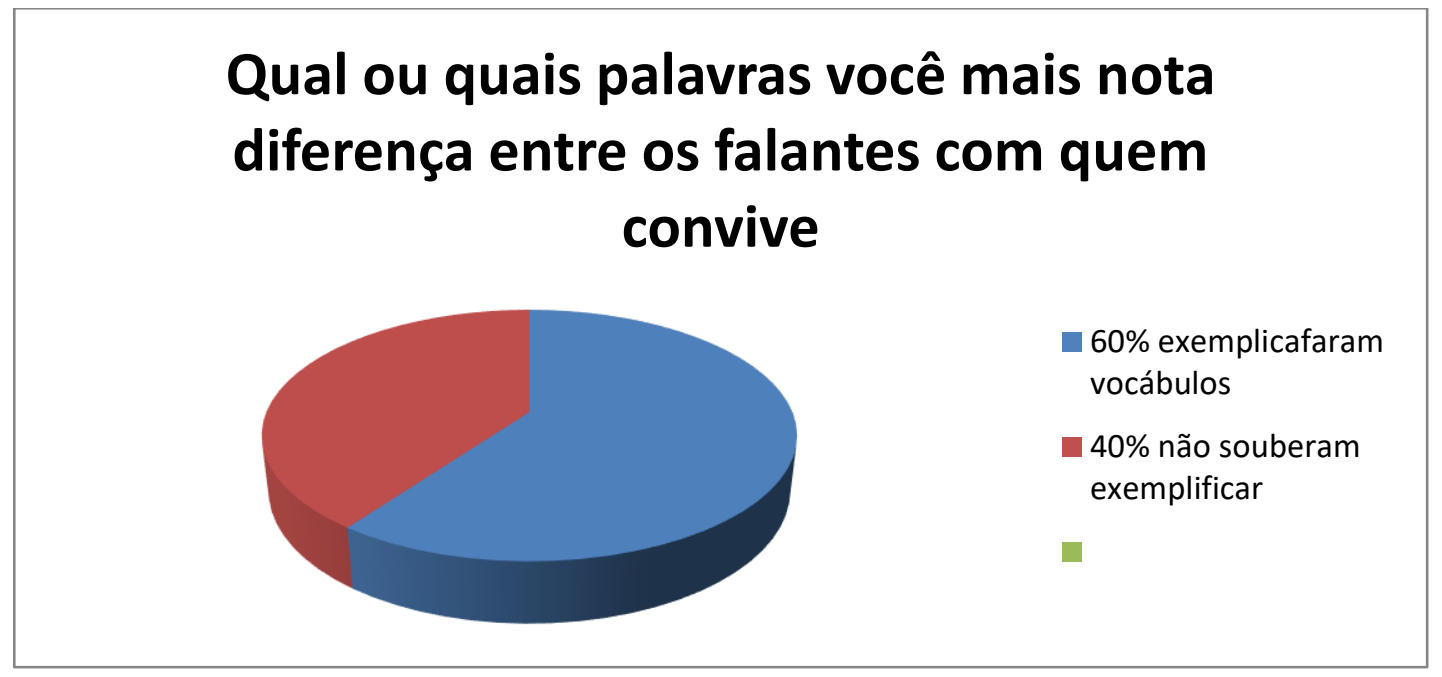

Fonte: autora

A partir desse tópico, além das identificações das variações linguísticas apresentadas pelas entrevistadas, já é possível constatarmos, através de parte das falas das participantes, a crença de "certo" e "errado" que o falante nativo de língua portuguesa traz consigo, reflexo do padrão que vem sendo imposto ao longo dos anos, construído e alimentado por um setor de nossa sociedade, o qual é tido como letrado e tem como integrantes, em sua maioria, indivíduos intelectuais e economicamente privilegiados.

O resultado dessa construção e disseminação elitizada do padrão considerado "culto" da língua portuguesa é a culminação no preconceito linguístico imposto aos falantes menos 
escolarizados, o que faz com que até eles mesmos acreditem estar "errados" em seus falares, contribuindo, assim, para enfraquecimento da desconstrução necessária ao combate ao preconceito linguístico, conforme o autor Bagno (1999) esclarece:

Do mesmo modo, muitos brasileiros acreditam que "não sabem português", que "português é muito difícil" ou que a língua falada aqui é "toda errada". E ao contrário dos demais preconceitos, que vêm sendo atacados com algum sucesso com diversos métodos de combate, o preconceito lingüístico prossegue sua marcha. (BAGNO,1999,p.70).

Analisaremos as questões 3 (três) e 4 ( quatro), respectivamente, neste mesmo tópico por apresentarem conteúdo correlacionados: Alguma vez você falou alguma palavra "errada" e alguém the corrigiu? Se sim, como foi? / Como você se sentiu diante dessa correção/ Qual a sensação que você tem ou teve? $\mathrm{O}$ resultado observado neste eixo, no que tange a hipótese de possíveis correções de palavras diferidas pelas entrevistadas, foi que todas as participantes relataram episódios contendo algum tipo de reprimenda em seus falares. Entretanto, somente uma das entrevistadas viu sob um aspecto positivo a correção a que foi submetida e, referente ao questionamento contido na questão pertinente à sensação de como se sentiu diante dessa correção, vejamos a descrição da sensação por ela sentida em suas palavras:

"Achei que foi bom porque aprendi, porque foi meu filho, estava me ajudando, me ensinando, não me senti mal não." (Margarida, 68 anos, $4^{\underline{0}}$ série fundamental I).

Em comparação a essa fala da entrevistada Margarida, observemos o contraste contido nos trechos das falas das outras entrevistadas, em que são claras as sensações negativas sentidas descritas por elas:

A gente fica chateado, né? Fica meio sem jeito com a gente, né? Fica bem chateado [...]”. (Crisântemos, 69 anos, $7^{\circ}$ série fundamental I).

"Envergonhada, eu pensei assim : Poxa vida, os outros conversam, eu converso com os outros, ninguém fala nada, agora, porque que eu falei ta falando que tá errado ? [...]”.(Violeta ,66 anos, $3^{\circ}$ série fundamental I).

"Péssimo, é horrível, eu acho muito horrível, né? [...]".(Azaleia ,5I anos, $4^{\circ}$ série fundamental I).

"Ah, eu me sentia humilhada, né? [...]". (Magnólia, 63 anos, $3^{\circ}$ série fundamental I).

O Gráfico 3 ilustra bem essa análise: 
Gráfico 3: Identificação de correções do falar das entrevistadas e sensações relatadas por elas .

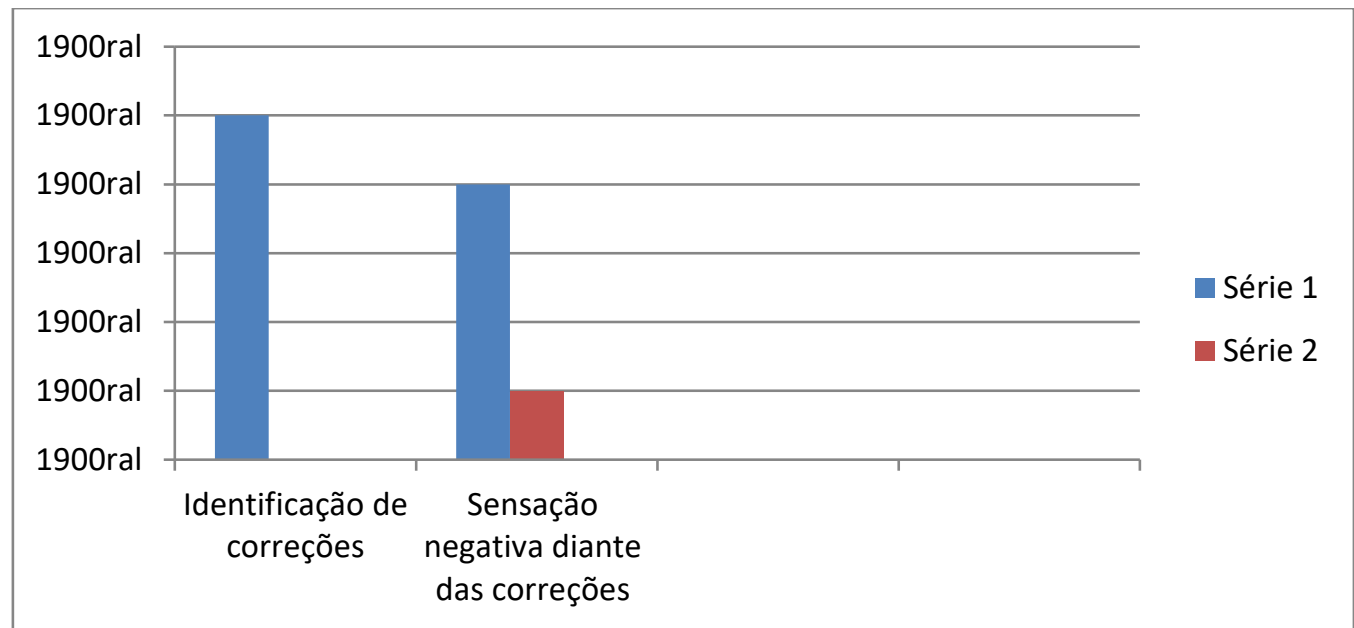

Fonte: autora

O que também chama atenção na análise deste tópico é a identificação da constante recorrente encontrada no conceito de "certo" e "errado" intrínseco na maioria dos falantes. Importa destacarmos que não há problemas no que tange a existência das variações linguísticas entre os falantes da língua portuguesa, mas sim em como se lida com isso e o que acarreta no conceito de valores nos indivíduos envolvidos, consoante explica Faraco (2008) “O problema está nas formas como lidamos com essa diversidade. O problema está na forma como representamos para nós essa diversidade. O problema está nas imagens saturadas de valores negativos que temos de nós como falantes" (FARACO, 2008, p. 18I).

Por fim, neste último tópico, podemos observar a unanimidade apresentada entre as entrevistada ao questionamento: Você acha que exista uma maneira "certa" de falar? Ao responderem todas de maneira afirmativa a essa questão, as participantes demonstraram a crença existente de "certo" e "errado", ao mesmo tempo em que reconhecem a diversidade das variações linguísticas de cada individuo. Vejamos trechos das entrevistas que evidenciam esse resultado:

"Existe, né? Tem o português certo, as palavras certas sim, eu falo bem errado". (Crisântemos, 68 anos, $4^{\circ}$ série fundamental I).

"Existe, só que a gente não sabe o português certo, então a gente fala completamente errado. Porque na leitura a gente resolve ler, a gente percebe o certo e o errado, mas é que você já acostumou com aquele hábito do errado [...]" (Violeta, 66 anos, $3^{\text {o }}$ série fundamental I).

"Eu acho de cada um, né? Cada um fala... igual eu, eu fui criada em fazenda 
com meus pais $[\ldots] ”$ (Azaleia, $5 \mathrm{I}$ anos, $4^{\mathrm{O}}$ série fundamental I).

“Ah bom, lá nos estudos tem ,né, a maneira certa , cientificamente e tudo, né, mas a gente sente mais à vontade falando do jeito da gente, né, não é mesmo ?Certo não é, né, mas a gente consegue falar assim." (Margarida 68 anos, $4^{\circ}$ série fundamental I).

"Se eu acho que tem uma maneira certa de falar? Ah, eu acho que cada um tem a sua, não é? Não é pra ter? [...]” (Magnólia, 63 anos, $3^{\circ}$ série fundamental I).

Essa postura observada nas respostas de todas as entrevistadas, referente ao reconhecimento delas no tocante à diversidade linguística e ao conceito da existência de uma forma "correta" em falar, é explicada por Bagno (1999) como um fator próprio de nossa cultura, a qual engloba a riqueza das variações linguísticas existentes na oralidade bem como fatores geográficos e socioeconômicos os quais, por vezes, acabam por incidir em preconceito linguístico para parte dos falantes. Vejamos a explicação nas palavras do autor:

Ora, a verdade é que no Brasil, embora a língua falada pela grande maioria da população seja o português, esse português apresenta um alto grau de diversidade $e$ de variabilidade, não só por causa da grande extensão territorial do país - que gera as diferenças regionais, bastante conhecidas e também vítimas, algumas delas, de muito preconceito [...] (BAGNO,1999,p.15).

Ratificando a ideia colocada anteriormente, podemos inferir, pelas palavras do autor, que

a diversidade da língua falada é um dos fenômenos o qual explica as respostas das entrevistadas nessa pesquisa. Esse fato aliado à regionalização a que cada uma delas pertence, suas classes sociais, seus conhecimentos de mundo, seus níveis de escolaridade, entre outros, construíram as percepções da língua falada por elas, diferenças essas, muitas vezes, vistas sobre o prisma do preconceito linguístico e não como diversidade cultural.

\section{CONSIDERAÇÕES FINAIS}

Com os resultados desta pesquisa, primeiramente, foi possível constatar a existência, ainda que inconsciente pelo falante, das variações linguísticas existentes na oralidade, conforme podemos evidenciar através dos dados obtidos nas entrevistas. Isso comprova o quanto a língua é heterogênea e acompanha os falantes de uma sociedade; ela evolui juntamente com os seus indivíduos, o idioma adequa-se às necessidades que surgem em seu uso na língua falada, extrapolando, assim, as normas escritas, as quais têm seu processo de evolução mais lento, uma vez que seguem outras regras mais engessadas e até mesmo burocratizadas.

Em um segundo momento, ficou claro a prática do preconceito linguístico que os falantes menos escolarizados sofrem em seus cotidianos. A partir das observações analisadas, através dos 
relatos das entrevistadas nessa pesquisa, também foi possível identificarmos o quão maléfico esta construção de "certo" ou "errado" ocasiona. Outro fator a ser considerado é a necessidade de desmistificação desses conceitos, ainda que se tenha alguma boa intenção por parte de quem faça correções linguísticas, e não se tenha a intencionalidade em discriminar o usuário da língua em sua modalidade coloquial, é preciso sim que os agentes praticantes dessas reprimendas entendam o preconceito linguístico contido implicitamente nelas.

\section{REFERÊNCIAS}

ANDREUCI.A.A.Preconceito, Discriminação e Intolerância no Brasil. Disponível em $\langle$ https://www.geledes.org.br/preconceito-discriminacao-e-intolerancia-no-brasil/> acesso em or de jul.de 2019 .

BAGNO, M. Preconceito Linguístico - O que é, como se faz. 48. Ed. São Paulo: Loyola, 1999.

FARACO, C. A. Norma culta brasileira: desatando alguns nós. São Paulo: Parábola, 2008.

LABOV, William; ASH, Sharon; BOBERG, Charles. The atlas of North American English. Berlin: Mouton de Gruyter, 2006.

LABOV, W. Padrões sociolingüísticos. Trad. de M. Bagno; M. M. P. Scherre; C. R. Cardoso. São Paulo: Parábola Editorial, 2008 [1972]. 